\title{
The use of clinical role-play and reflection in learning therapeutic communication skills in mental health education: an integrative review
}

This article was published in the following Dove Press journal:

Advances in Medical Education and Practice

\author{
Solrun Brenk Rønning' \\ Stål Bjørkly ${ }^{1,2}$ \\ 'Faculty of Health Sciences and Social \\ Care, Molde University College, Molde, \\ Norway; ${ }^{2}$ Centre for Research and \\ Education in Forensic Psychiatry, Oslo \\ University Hospital, Oslo, Norway
}

Background: An important goal in mental health education is for students to develop their ability to provide care and help to people with different degrees of mental problems. Positive experiences with the use of clinical role-play and subsequent reflection inspired us to investigate whether previous empirical studies had evaluated similar methods of teaching and to scrutinize the effects on students' development of therapeutic skills and clinical reflection.

Method: An integrative review was conducted to search the literature for findings from both qualitative and quantitative research. Systematic searches of literature were done in Ovid (MEDLINE, PsycInfo), Cinahl, Cochrane, ScienceDirect, SweMed, Norart, ProQuest, and Google Scholar.

Results: The systematic literature search provided 42 full-text articles and four articles met the inclusion criteria. The results suggest that role-play in health education enhances students' therapeutic and communicative skills. Nevertheless, there is limited research on the use of roleplay in teaching therapeutic skills, and few studies that investigate how role-play affects students' reflections on own practice. The literature search did not discover studies investigating whether practicing role-play in educational settings has consequences for clinical practice. Conclusion: Based on this current review, role-playing in supervised groups seems to promote reflection and insight not only for students in the patient and therapist roles, but also for peers observing the group sessions. According to the included studies, clinical roleplay facilitates helper-user equality and increases students' involvement, self-efficacy, and empathic abilities in mental health practice.

Keywords: review, education, nursing, role-play, reflection, therapeutic communication

\section{Introduction}

In mental health education students practice skills in a safe environment in order to become safe, predictable and competent practitioners. However, students are likely to have conflicting experiences as they move between the classroom and practice in terms of understanding the user's experience and trying out skills they have learned. ${ }^{1-3}$ It has been emphasized for decades that the development of phenomenological understanding and therapeutic attitude is best achieved through practice-based training in groups, eg, Rogers. ${ }^{4}$ Group-based reflection in learning therapeutic communication skills may be implemented through teaching formats, such as simulation techniques, role-play and reflective practice. Below we discuss briefly some aspects of these formats with emphasis on hallmarks and differences.
Correspondence: Solrun Brenk Rønnin Faculty of Health Sciences and Social Care, Molde University College, PO. Box 2110 , Molde NO-6402, Norway

Tel +477 I 214040

Email solrun.b.ronning@himolde.no 


\section{Simulation techniques}

Simulation involves performing a role in an interaction, either through roleplaying or by using a professional, trained standardized patient. ${ }^{5}$ The idea of using standardized and simulated patients originally came from the neurologist Howard Barrows. 5,6 Barrows defined a "simulated patient" as a regular person who has been trained to present symptoms and signs of a particular diagnosis. 5,7 The Researchers in Clinical Skills Assessment defined a "standardized patient" as a person with or without a certain disease who has been trained to describe either their own problems or those based on observations of other patients. ${ }^{5,8}$ In roleplays, students play the role of a patient they have met, thus exploring attitudes and feelings as part of professional development. $^{5}$ At the part-time continuous education program of mental health care at Molde University College, supervised reflection groups, which include clinical roleplay and joint clinical reflections on the actual role-play, have been an important part of the education for 20 years. Students bring anonymized case descriptions of patients from their daily work in mental health care to their reflection group and practice psychotherapeutic communication approaches by the use of clinical role-play, clinical reflection and supervision. The student who brings the case role-plays the patient, and fellow students role-play the therapist and other members of the patient's social network (Table 1).

These simulation techniques share important similarities, but there are also major differences. The main differences are the role the student takes in the interaction, whether reflection is used as a significant part of the simulation, and whether practicing psychotherapeutic communication approaches are essential in the role-play.

As mentioned before, students are likely to have conflicting experiences as they move between class and practice. $^{1,9}$ This study will focus on role-play, which is one of the most established forms of simulation and has been used for decades in teaching students clinical skills. ${ }^{1,3,10}$ For almost 100 years, reflective thinking has been described as a continuous assessment of knowledge. ${ }^{11}$ Yet, there seem to be few studies that investigate methods combining reflection and role-play in teaching mental health, and whether doing so, bridges the gap between knowledge from class and practice.

\section{Guided role-play in teaching therapeutic skills}

The use of role-play in mental health education allows students to become active participants and at the core of their learning. ${ }^{1}$ Because textbook descriptions cannot adequately communicate what it feels like to be disturbed or in conflict, Scheffler ${ }^{10,12}$ introduced a method for teaching the interview of a psychiatric patient in early 1970s. Students played the roles of both the client and the interviewer. At that time, students in training were normally asked to identify with the role of the professional, and it was unusual to ask students to role-play the client. In Scheffler's model, students were assigned roles that involved doing a subjective selection of the characteristics of a specific diagnosis and explaining and enacting the selection in role-play. The method was successful in decreasing students' anxiety, enabling them better to understand concepts and skills and enhancing identification with the client. ${ }^{10,12}$ Martin and Kahn ${ }^{13}$ also described a method whereby the students role-played patients and doctors during simulated medical interviews. They indicated that this approach helped students increase their insight into patients' behaviors and doctors' common reactions. Wasylko and Stickley ${ }^{14}$ described experiences with the use of role-play in the education of psychiatric nurses. They argued for more drama in education because it equalized the position of participants, teachers and students and promoted empathetic understanding between

Table I Simulation techniques

\begin{tabular}{|l|l|l|l|l|l|}
\hline & $\begin{array}{l}\text { Students role- } \\
\text { play the clini- } \\
\text { cian/therapist }\end{array}$ & $\begin{array}{l}\text { Students } \\
\text { role-play } \\
\text { the patient }\end{array}$ & $\begin{array}{l}\text { Other than stu- } \\
\text { dents role-play } \\
\text { the patient }\end{array}$ & $\begin{array}{l}\text { Subsequent } \\
\text { reflection } \\
\text { used as means }\end{array}$ & $\begin{array}{l}\text { The use of psychotherapeutic } \\
\text { communication approaches in } \\
\text { the role-play }\end{array}$ \\
\hline Standardized patient & $\mathrm{X}$ & & $\mathrm{X}$ & & \\
Simulated patient & $\mathrm{X}$ & $\mathrm{X}$ & & \\
Role-play & $\mathrm{X}$ & $\mathrm{X}$ & $\mathrm{X}$ & $\mathrm{X}$ \\
Reflection groups at & $\mathrm{X}$ & $\mathrm{X}$ & & & \\
Molde University College & & & & & \\
\hline
\end{tabular}

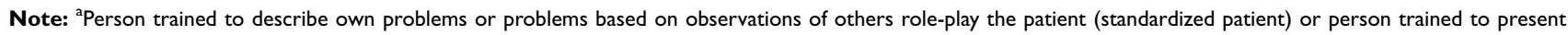
symptoms of particular diagnosis role-play the patient (simulated patient). 
all participants. They also believed that it could be a valuable tool for the development of empathy and reflective practice. Saeterstrand ${ }^{15}$ outlined how role-play prepared nursing students for mental health practice. Roleplay prepared students for difficult situations that could arise in the clinic, and students switched from an individual- and symptom-oriented focus to one on interpersonal relationships. In addition, they became familiar with their own reactions and vulnerabilities. This practice relates to the humanistic and person-centered philosophy of Carl Rogers. ${ }^{16}$ Rogers believed in the individual's power for healing and learning. Role-play enhances and facilitates personal and professional growth as it increases students' ability to learn what it is like to be in others' shoes and, through that experience, develops empathy and reflection. As a result of this kind of learning, the student develops greater capacity for treating others with the respect and understanding required in mental health care. ${ }^{1}$

\section{Reflective practice}

There are different definitions of reflection. Dewey ${ }^{11}$ promoted the concept of reflective thinking in the first half of the 20th century and described it as an active, continuous and careful assessment of any belief or form of knowledge in the light of the justification and conclusion that supports the belief or knowledge. ${ }^{17}$ Mann, Gordon and MacLeod ${ }^{17}$ emphasized that models for reflection include critical reflection on experiences and practices that show the need for more learning. As professional identity evolves, reflection can help integrate different forms of learning that require professional understanding and perspective, and that value the professional culture. Integrated knowledge depends on an active approach to develop new understanding and new knowledge to add to existing knowledge. Reflection helps a professional to become more self-regulated, conscious and self-critical. ${ }^{17}$ Schön ${ }^{18}$ defined clinical reflection related to action as "reflection-in -action," whereby students reflect on their own experiences during clinical practice and then, after the clinical experience, reflect on the actions they took, critically examining what they did and learned, or what worked and what did not work.

A preliminary search of the literature showed that simulation techniques are highly important in clinical studies, and there were quite a few studies on the use of standardized patient and simulation. However, there was less, or hardly any, research on the use of role-play coupled with subsequent reflection for practicing psychotherapeutic communication skills. Based on the positive experiences at Molde University College and the scarcity of publications on this approach, we conducted an integrative review of the literature with the following research questions:

- Have previous empirical studies evaluated similar methods of teaching?

- Does clinical role-play have a positive effect on students' development of therapeutic or communicative skills?

- Does role-playing the patient has a positive impact on therapeutic skills and clinical reflections?

\section{Method}

An integrative review was chosen because we wanted to scrutinize the literature for findings from both qualitative and quantitative research. This type of review is important in evidence-based practice as it invites investigating different aspects of a phenomenon by including different methods. ${ }^{19}$ We used the five stages of review that Whittemore and $\mathrm{Knafl}^{19}$ recommended for integrative reviews: 1) problem identification, 2) literature search, 3) data evaluation, 4) data analysis, and 5) presentation in the traditional introduction-method-results-discussion structure. "Problem identification" is presented in the introduction and method sections, "Literature search" in the method section, "Data evaluation" in the results section, and "Data analysis" and "Presentation" in the discussion section. In addition, the process of the review, including the identification and selection process, was based on the PRISMA statement and the PRISMA flow chart. ${ }^{20}$

\section{Problem identification}

Scheffler, ${ }^{12}$ Martin and $\mathrm{Kahn}^{13}$ and McNaughton et $\mathrm{al}^{5}$ emphasized the importance of students role-playing the patient to help them explore attitudes and feelings as part of their professional development. The recognition of attitudes and feelings following role-plays seems similar to Dewey's ${ }^{11}$, Schön's ${ }^{18}$ and Mann and colleagues ${ }^{17}$ definitions of reflection. Hence, we found it natural to combine clinical role-play and clinical reflection as research aims for this review. Because there are different therapeutic and communicative approaches, we included empirical research that investigated the teaching of therapeutic communication skills that aimed to help persons with mental health problems.

The inclusion criteria were that the studies had to report empirical results from 1) the educational use of role-play and subsequent clinical reflection, 2) within the context of training therapeutic communication skills 
and 3) for university students studying mental health on at least the bachelor's level.

The review excluded articles that were not empirical research articles; investigated "standardized patients"; did not address teaching mental health; investigated simulation using manikins or avatars; did not investigate clinical role-play; investigated just reflection; investigated roleplay, but failed to include reflection; and investigated simulation due to physical symptoms (see Table 2 in data evaluation).

\section{Literature search}

Papers in English or Scandinavian languages were included. Literature on standardized patient and classic simulation, as defined in the introduction, were excluded, as were studies investigating role-playing without focusing on reflection.

To find as many studies as possible, there were no limitations concerning research methods used in the studies. It was also desirable to find research that was as new as possible, but, because research seemed to be scarce on the subject, there were no limitations on the year of the studies. Systematic searches of literature were done in Ovid (Medline, PsycInfo), Cinahl, Cochrane, ScienceDirect, Swemed, Norart, Proquest and Google Scholar with the following keywords, in different combinations (see Figure 1): mental health, mental health nursing, psychiatry, student, teaching, training, education, supervision, guidance, reflection, reflection group, roleplay, drama, meaning, outcome, effect, percept, experience, learning, therapeutic skills, helping skills, psychotherapy, and therapy. The searches were done between April 2016 and April 2018. We conducted an update on October 1, 2018.

\section{Data evaluation}

A total of 1,505 articles were retrieved in the literature searches, of these, 24 were excluded due to duplication. Three articles were identified by hand searches by checking the reference lists of the full-text articles. The first author did the first stage of analysis by evaluating titles and abstracts of 1,484 articles. In cases of doubt, she consulted the second author for a joint decision. A total of 1,442 articles were excluded because they covered neither reflection in teaching mental health care or therapeutic approaches nor the use of role-play and reflection. In Stage 2, the first and second authors did an independent evaluation of 42 full-text articles. Consensus decision yielded 15 articles to be scrutinized, organized and coded in a literature matrix. They were categorized according to country of origin, purpose of the study, method, participants, results and conclusion. In addition, a decision was made on whether they presented role-play and clinical reflection in teaching or learning therapeutic skills for university students. The further analysis (Stage 3) was done in three steps based on independent assessments of inclusion by the first and second author and consensus decision in case of disagreement. First, studies investigating reflection were sorted into one group $(n=3)$ and the use of role-play in teaching therapeutic skills in mental health care $(n=12)$ in another. Second, studies that investigated role-play were divided into two groups: role-play using other than students in the patient role $(n=5)$ and role-plays with students in the patient role $(n=7)$. Finally, studies investigating the effect of role-playing on both the therapist and patient in the context of learning therapeutic communication skills and students' reflections $(n=4)$ were analyzed by the use of a final literature matrix Figure 2, Tables 2 and 3).

\section{Results}

The systematic literature search provided 42 full-text articles that were scrutinized (see Figure 2). Four articles met the inclusion criteria (see Table 3 ) and 38 were excluded (see Table 2). The origin of the included studies was one from Norway, ${ }^{21}$ one from Australia ${ }^{22}$ and two from the USA. ${ }^{23,24}$ The studies were published between $1993^{24}$ and 2016 . $^{23}$ Two of the studies used quantitative methods ${ }^{22,24}$

Table 2 Number and reason for excluded full-text articles

\begin{tabular}{|c|c|c|c|c|c|c|}
\hline $\begin{array}{l}\text { Investigated } \\
\text { standardized } \\
\text { patients, } \\
\text { not role-play }\end{array}$ & $\begin{array}{l}\text { Did not address } \\
\text { teaching } \\
\text { mental health }\end{array}$ & $\begin{array}{l}\text { Not } \\
\text { research }\end{array}$ & $\begin{array}{l}\text { Investigated } \\
\text { simulation } \\
\text { using manikins } \\
\text { or avatars }\end{array}$ & $\begin{array}{l}\text { Did not investigate } \\
\text { clinical role-play }\end{array}$ & $\begin{array}{l}\text { Investigated } \\
\text { reflection, } \\
\text { not role- } \\
\text { play }\end{array}$ & Others $^{a}$ \\
\hline 4 & 2 & 9 & 3 & 12 & 5 & 3 \\
\hline
\end{tabular}

Note: 'Studied simulation to recognize physical symptoms, did not investigate role-play, investigated role-play with students' role-playing patient role, but failed to include its impact on clinical reflection. 


\begin{tabular}{|c|c|c|c|c|c|c|c|c|}
\hline & And & & & And & & An & & \\
\hline $\begin{array}{l}\text { Mental health } \\
\text { Mental health nursing } \\
\text { Mental health nurs* } \\
\text { Psychiatr* }\end{array}$ & Or & Student* & $\begin{array}{l}\text { Teach* } \\
\text { Train* } \\
\text { Educat* } \\
\text { Supervision } \\
\text { Guid* }\end{array}$ & Or & $\begin{array}{l}\text { Reflect* } \\
\text { Reflection } \\
\text { group* } \\
\text { Role* play* }_{\text {Drama }}\end{array}$ & Or & $\begin{array}{l}\text { Learn* } \\
\text { Therapeutic skill* } \\
\text { Help* skill*} \\
\text { Psychother* } \\
\text { Therap* }\end{array}$ & Or \\
\hline
\end{tabular}

Figure I Literature search ${ }^{\mathrm{a}}$

Notes: ${ }^{a}$ Example on search done in Ovid. Limits: peer-reviewed; 1860 to current; English or Scandinavian language.

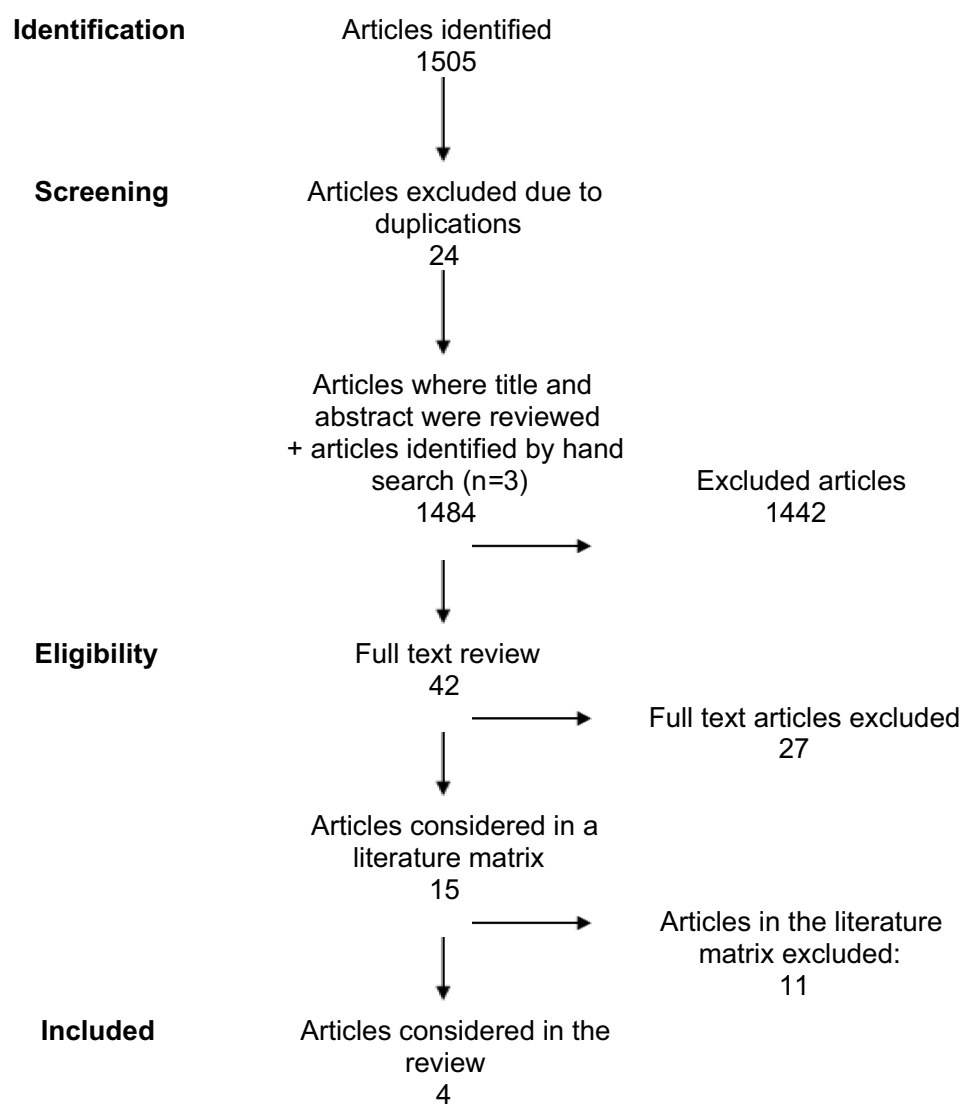

Figure 2 Identification and selection process based on the PRISMA flow chart. Adapted from Moher D, Liberati A, Tetzlaff J, Altman DG, The PRISMA Group. Preferred reporting items for systematic reviews and meta-analyses: the PRISMA statement. PLoS Med. 2009;6(7).20

and two used qualitative methods. ${ }^{21,23}$ The number of participants varied from $31^{24}$ to 107 participants. ${ }^{22}$ Three of the four studies incorporated written surveys or questionnaires, ${ }^{22-24}$ the fourth one conducted focus group interviews $^{21}$ (see Table 3). The included articles covered four topics: role-playing in learning helping skills, a roleplay-based approach to teach clinical communication, role-play activities concerning auditory hallucinations, and the use of role-play to teach psychiatric interviews.

\section{Role-playing in learning helping skills}

Guttormsen, Hoifodt, Silvola and Burkeland ${ }^{21}$ investigated whether the course "First aid in case of suicide," where role-play was an important method of teaching, was suitable for medical students. Forty-seven $(62 \%)$ of 76 students who participated in the course were interviewed in focus groups consisting of 2-12 students. The participants said that they were more prepared to help persons in danger of suicide after the course. They expressed that 


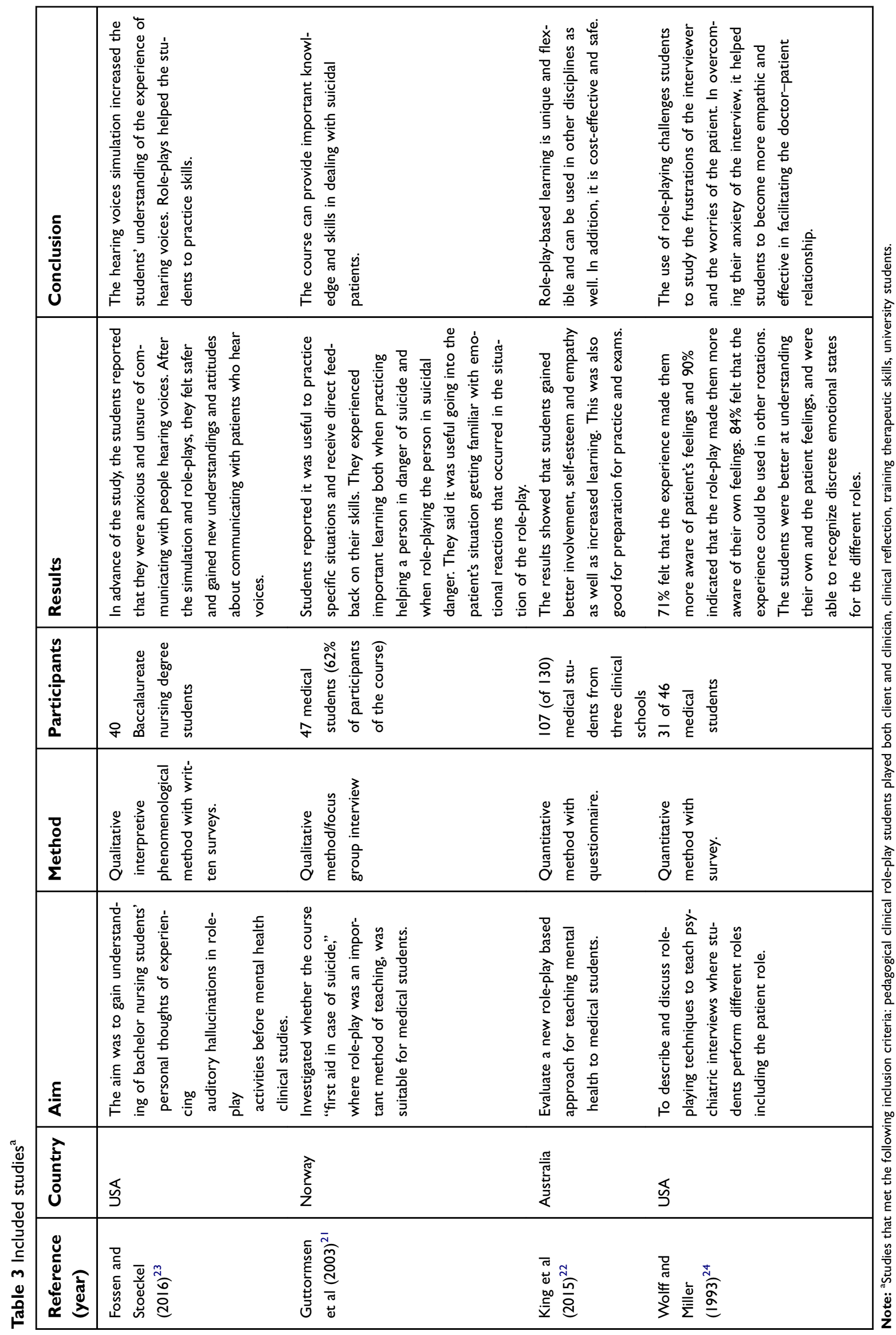


trying out important knowledge in role-plays increased their understanding and raised awareness about their own feelings. This improved their professional self-efficacy. Participants in the study reported it was useful to practice specific situations and receive direct feedback on their skills. They experienced important learning both when practicing helping a person in danger of suicide and when role-playing the person in suicidal danger. The participants found it useful taking on the patient's situation and thus getting familiar with emotional reactions that occurred in the situation of the role-play. ${ }^{21}$

\section{A role-play-based approach to teach clinical communication}

Using an evaluation questionnaire, King, Hill and Gleason $^{22}$ evaluated a new role-play-based approach to teaching clinical knowledge and communication in mental health for medical students. The role-play-based learning (RBL) method contained a batch of teaching modules that each included the narrative of a patient and guidelines for the facilitator. The students received scenarios for the patient, relative or corresponding health professional a week ahead of the session. The students role-played both the doctor and the patient roles. After the role-play, there was a group discussion and a feedback session. In total, 130 medical students from three educational institutions received the questionnaire. The questionnaire asked about the number of sessions attended and then asked the participants to respond to a selection of statements using a five-point Likert scale $(1=$ strongly disagree; $5=$ strongly agree $)$. Finally, the students were asked five open-ended questions and two structured questions. A total of 107 students (79\%) completed the questionnaire. They had attended an average of 5.4 of the 6 sessions. The participants were positive about the features of the sessions and found them engaging, informative and relevant. Their experiences in the role-plays were evaluated as challenging but valuable. They reported that by experiencing the patient role, they developed greater understanding of the patient's point of view. Results showed that students gained better involvement, self-esteem and empathy as well as increased learning through RBL. It was also good preparation for practice and exams. The results also indicated that RBLis unique and flexible and could be used in other disciplines as well. In addition, it is cost-effective and safe. ${ }^{22}$

\section{Role-play activities concerning auditory hallucinations}

Fossen and Stoeckel $^{23}$ investigated bachelor nursing (BSN) students' personal experiences of hearing voices through simulation and role-play activities related to this. The study used an interpretive phenomenological approach and data were collected through written surveys replied to by $40 \mathrm{BSN}$ students in their first mental health didactic course. The intervention of the study was a hearing-voices simulation package and role-play activities developed by one of the researchers. It consisted of 1) an orientation to the hearing voices package, 2) participation in the simulation, 3) participation in role-plays, 4) a debriefing session and, finally, 5) written surveys. During the simulation, the participants wore headphones and experienced an imitation of hearing voices while they completed different tasks. In the role-play session, a student experiencing hearing voices was admitted to the emergency unit for evaluation. The participants worked in pairs with one playing the role of a nurse, and the other, the role of a person experiencing auditory hallucinations. In the debriefing after the role-play, students could ask questions and receive answers. Finally, data for the study were collected through surveys. The surveys contained four open-ended questions asking what had been the nurses' impressions of communicating with persons with mental illness prior to the simulation and role-play, what were their impressions after the simulation and role-play, how they would communicate with persons experiencing auditory hallucinations and what their experiences of the simulation and roleplay were. In advance of the study, the students had reported that they were anxious and unsure about communicating with people hearing voices. After the simulation and role-plays, they felt safer and gained new understandings and attitudes about communicating with patients who hear voices. Students explained how acknowledgment of a person hearing voices changed their way of communicating. They also explained how their perspectives changed as a result of the simulation and role-play and that they gained more empathy and respect for patients with mental illness. ${ }^{23}$

\section{The use of role-play to teach psychiatric interviews}

Wolff and Miller ${ }^{24}$ described and discussed role-playing techniques for teaching psychiatric interviews where medical students performed different roles, including the 
patient role. They then conducted a quantitative study whereby a survey was designed and distributed to students who had participated in role-playing exercises. Third-year medical students in their clinical psychiatry rotation at an inpatient unit met with the ward's physician once a week for supervision and instruction. During the first meetings, they used role-playing to learn the patient interview. The physician set the roles and started by taking the role of the patient. After 10 mins they changed roles and one of the students was given the opportunity to play the patient. At the end of the meeting, they stopped the interview and discussed the session. A survey was designed and distributed to 46 students: $31(68 \%)$ replied to the survey. Of the 31 responses, $71 \%$ felt that the experience had made them more aware of patients' feelings, and $90 \%$ indicated that the role-play had made them more aware of their own feelings; $84 \%$ felt that the experience could be used in other rotations; $94 \%$ used the skills learned during their rotations and $74 \%$ said they could utilize the skills in other rotations. The students felt that the interviewer role was more difficult to portray than the patient role, but that the exercise was a good method for teaching interviews. The results signify that for those students who replied to the survey, the role-playing was considered useful. The students found they were better at understanding their own and patients' feelings. The results also showed that the skills could be beneficial in other medical school rotations as well. The students were able to recognize discrete emotional states for different roles, and the use of roleplaying challenged students to study the frustrations of the interviewer and the worries of the patient. In overcoming students' anxieties regarding interviews, it helped them become more empathic and effective in facilitating the doctor-patient relationship. ${ }^{24}$

The purposes of the included studies were slightly dissimilar. Three of the studies investigated role-play as an approach and technique of teaching, while the last investigated the students' experience with role-play as a learning activity. Despite the aims of the studies were a little different, the results seemed to match. All of the studies report that students developed their attitudes and therapeutic understanding, and that the use of role-play increased the students' learning. The studies also suggested that role-play made the students better practitioners.

\section{Discussion}

As mentioned above, an important goal in mental health education is for students to develop their ability to provide care and help people with different degrees of mental problems and disorders. That there seem to be different approaches to achieve this inspired us to do an integrative review of the literature to analyze empirical findings on the use of role-play with subsequent reflection on developing psychotherapeutic attitudes and skills. The results suggest that role-play enhances students' therapeutic and communicative skills. Nevertheless, there is limited research on the use of role-play in teaching therapeutic skills and few studies that investigate how role-play affects students' reflections on own practice. The literature search also did not discover studies investigating whether practicing role-play in educational settings has consequences for clinical practice.

The preliminary literature search found some studies that had investigated the effect and outcomes of therapeutic skills training, but not its influence on reflection. ${ }^{25-27}$ There seems to be scarce research on the benefits of fellow students participating in reflections and feedback following a role-play. In this review, studies exploring role-plays with students in both the role of the therapist and the patient were included. It was interesting to discover that from all the full-text articles considered, only studies investigating role-plays where student played both roles had findings related to the development of students' reflections.

According to two of the studies, it looks like role-play has the potential to enhance students' therapeutic and communicative skills, eg, Guttormsen et al; King et al. ${ }^{21,22}$ Students seem to experience important learning by putting themselves in the patient's position and, by that, discovering their own reactions to the situation..$^{21,23}$ In addition, students appear to become more empathic and better at understanding their own and their patients' feelings through the use of role-play. ${ }^{22,24}$ Experiences from roleplay seem to increase students' reflections on their own practice and those reflections naturally affect how they approach others. ${ }^{21-24}$ So, how would role-play and subsequent reflection affect students' clinical practice? In what ways would patients notice changes in a health professional after RBLcompared to one without this experience? When students get the opportunity to "perceive" a patient's situation, it may be an important doorway to familiarizing themselves with other persons' experiences. On the other hand, some students may be blinded by their own experience from a role-play and lose or overlook others' experiences. Dewey ${ }^{11}$ described reflective thinking as an active, continuous and careful assessment of knowledge. Mann 
et $\mathrm{al}^{17}$ described reflection as an active approach to developing new understanding to existing knowledge. All of the studies included in this review investigated role-playing from the position of both therapist and patient. Still, none of the studies reported students' reflections as described by Dewey and Mann and colleagues. ${ }^{11,17}$ Despite that results showed that students' reflection increased through roleplaying and that students became more confident and better at communicating with patients after having experiences from this educational intervention.

A role-play-based reflection model developed at Molde University College was briefly presented in the introduction of this article. One main difference between that model and the ones investigated in the studies of this review is that instead of practicing procedures and daily clinical assessments, the aim of our approach is to apply clinical communication from basic principles of four psychotherapeutic perspectives. By learning more than one psychotherapeutic perspective, the students obtain a wider understanding of the other and the interaction between them. The students are advised to use more than one psychotherapeutic perspective, particularly when one perspective fails to establish and secure a growth-oriented relationship. Other differences are that our training is continuous over 2 years and that it is required that the student role-playing the patient actually is well acquainted with the actual patient.

In this review only studies investigating role-plays where students played both the therapist and the patient role were included. The findings indicate that students seem to experience important learning and appear to be more empathic by putting themselves in the patient's position. Mental health care education that incorporates roleplaying should give students the opportunity to experience and understand a patient by testing the patient role. By role-playing a patient already known to the student, it becomes easier for the student to come close to the other person's views, perceptions and emotions. This may inform his or her understanding and capacity to help the other person. It is our experience that by learning different therapeutic perspectives it is more likely that students develop therapeutic flexibility.

The literature search in this review did not provide any research on models like the clinical supervision model at Molde University College. In general, research on the use of clinical role-play and clinical reflection seems limited. There might be different reasons for that. It could be that this method of teaching is rare. Another explanation could be that this model of teaching is so common that none ever cared to do research on it.

The most obvious suggestion for future research is to increase the number of studies. There are enormous human and financial resources invested in mental health education. We would be surprised if the scarcity of research on role-play reflects the real picture of what goes on in this type of education. Hence, our first suggestion is to conduct descriptive research on the presence and rates of this educational approach. Moving to another research design, controlled studies with monitoring of the effect of roleplay are called upon. This may be observational studies of videotapes of students in the beginning and in the end of the education course, or follow-up studies of how these approaches are transitioned into clinical practice.

\section{Limitations}

\section{Limitations of the retrieved studies}

Even though results found that students did reflect differently after they had experienced RBL, none of the retrieved studies aimed specifically to investigate how role-play affected students' reflection. Three of the articles did not demonstrate how the role-plays were acted out; only Wolff and Miller ${ }^{24}$ had excerpts of role-play in the article.

Fossen and Stoeckel ${ }^{23}$ collected data after the students had been debriefed with one of the researchers following the role-plays. This could have affected the results. The use of surveys could have biased the data saturation since they did not get the chance to ask follow-up questions like an interview design would allow for. On the other hand, collecting open-ended-questions data from 40 informants yielded a larger sample than one usually finds in qualitative interviews. Finally, there was no information concerning drop-outs.

Guttormsen and colleagues ${ }^{21}$ interviewed students in focus groups to gather data for the study. However, the dynamics in the group may have affected the findings. Some may have had a stronger position than others in the group, and this could have influenced what the students said. The fact that one of the interviewers was the students' teacher may also have caused bias. These limitations were all mentioned in the article. In addition, the themes of the interview guide were inadequately described in the article, and this hampers interpretability and complicates the assessment of the internal validity of the study.

Wolff and Miller ${ }^{24}$ emphasized the limitation that only $67 \%$ of the students responded to the survey. In addition, 
since the students did not have an alternative method of learning and there was no control group, lack of comparability complicates the evaluation. The fact that only descriptive statistics were used reduces the quality of this research.

King, Hill and Gleason ${ }^{22}$ collected questionnaire data from 107 of 130 students completing psychiatric rotation. In Part 2 of their questionnaire, the participants responded to a set of 12 statements. Ten statements were about RBL, one about problem-based learning (PBL) and one about whether the student preferred topic lectures rather than role-playing. Cronbach's alpha coefficient of internal consistency for all 12 items was 0.81 . Since the questionnaire had more than one category (RBL, PBL and topic lectures), it may not be reliable to report alpha for Part 2 of the test as a whole. The large number of questions would also increase the value of alpha. ${ }^{28}$ They presented results that show that respondents were positive about all items of RBL compared to PBL. However, they rated many more items of the RBL than for PBL. If they had rated the same number of items of RBL and PBL, the results could perhaps have been different.

\section{Limitations of the integrative review}

The literature search provided few studies that investigated the use of clinical role-play in the development of therapeutic skills, reflection and understanding. A reason for the scarcity of results could be that we should have used other key words or other relevant databases that we did consider. Another limitation could be that only one researcher reviewed the titles and abstracts, so that important findings could have been missed at that stage. An additional limitation could be that we used similar pedagogical methods, which could have affected the data analysis. An asset in using integrative review is that the approach allows for a mix of different methodologies. The mix of methods in an integrative review has the potential to result in a comprehensive description of complex approaches and important theories thus providing a broader picture of a phenomenon, which can be valuable in evidence-based practice. However, the combination of different methods increases the risk of failure and requires a systematic and well-formulated approach to the data analysis. ${ }^{19}$ To avoid this limitation, we used the five stages of review that Whittemore and Knafl recommended for integrative reviews.

\section{Conclusion}

The aim of this integrative review was to investigate how clinical role-play influenced students' development of therapeutic communication skills and clinical reflection. We only found four studies meeting our inclusion criteria. However, this review illuminates pedagogical processes with role-playing, supervision and reflection in the development of therapeutic, professional and interpersonal competence. Role-playing in supervised groups seems to promote reflection and insight not only for students in the patient and therapist roles, but also for peers observing the group sessions. According to the included studies, clinical role-play facilitates helper-user equality and increases students' involvement, self-efficacy and empathic abilities in mental health practice. Further research is called for concerning mental health nursing students' experiences with role-playing both the therapist and patient roles. It would be especially important to investigate this in the context of learning psychotherapeutic approaches and their possible impact on students' development of clinical reflection and practical skills.

\section{Acknowledgment}

We declare that we had no funding for this research.

\section{Disclosure}

The authors report no conflicts of interest in this work.

\section{References}

1. Wasylko Y, Stickley T. Promoting emotional development through using drama in mental health education. In: Stickly $\mathrm{T}$, Basset $\mathrm{T}$, editors. Teaching Mental Health. Chichester: John Wiley \& Sons, Ltd; 2007:297-309. doi:10.1002/9780470713617.ch25

2. Kinney M, Aspinwall-Roberts E. The use of self and role play in social work education. $J$ Mental Health Training Edu Pract. 2010;5 (4):27-33. doi:10.5042/jmhtep.2010.0688

3. Saunder L. Online role play in mental health education. $J$ Mental Health Training Edu Pract. 2016;11(1):1-9. doi:10.1108/JMHTEP07-2015-0031

4. Rogers CR. Client-Centered Therapy. Boston: Houghton \& Mifflin; 1951.

5. McNaughton N, Ravitz P, Wadell A, Hodges B. Psychiatric education and simulation: a review of the literature. Can J Psychiatry. 2008;53 (2):85-93. doi:10.1177/070674370805300203

6. Barrows HS, Abrahamson S. The programmed patient: a technique for appraising student performance in clinical neurology. J Med Educ. 1964;39:802-805.

7. Barrows H. How to Design a Problem-Based Curriculum for the PreClinical Years. New York (NY): Springer; 1985.

8. RCSA. Consensus statement for the researchers in clinical skills assessment (RCSA) on the use of standardized patients to evaluate clinical skills. Acad Med. 1993;68:475-477. 
9. Landy RJ. Persona and Performance: The Meaning of Role in Drama, Therapy and Everyday Life. London: J Kingsley; 1993.

10. Scheffler LW. Helping counselors understand emotional disturbance through roleplaying. Couns Educ Supervision. 1973;13(1):72-75. doi:10.1002/j.1556-6978.1973.tb01586.x

11. Dewey J. How We Think: A Restatement of the Relation of Reflective Thinking to the Educative Process. Massachusetts: DC. Heath; 1933.

12. Scheffler LW. Being is believing: playing the psychiatric patient. J Psychiatr Educ. 1977;1(1):63-67.

13. Martin P, Kahn J. Medical students as role playing patients. Acad Psychiatry. 1995;19(2):101-107. doi:10.1007/BF03341538

14. Wasylko Y, Stickley T. Theatre and pedagogy: using drama in mental health nurse education. Nurse Educ Today. 2003;23:443-448.

15. Sæterstrand T. Roleplaying as pedagogical method (Rollespill som pedagogisk metode). Sykepleien. 2007;95(5):70-71. doi:10.4220/ sykepleiens.2005.0001

16. Rogers C. Freedom to Learn. New York (NY): MacMillan College Inc; 1994.

17. Mann K, Gordon J, MacLeod A. Reflection and reflective practice in health professions education: a systematic review. Adv Health Sci Educ. 2009;14(4):595-621. doi:10.1007/s10459-007-9090-2

18. Schön D. The Reflective Practitioner. 2nd ed. San Francisco: Jossey Bass; 1991

19. Whittemore R, Knafl K. The integrative review: updated methodology. $J$ Adv Nurs. 2005;52(5):546-553. doi:10.1111/jan.2005.52.issue-5

20. Moher D, Liberati A, Tetzlaff J, Altman DG, The PRISMA Group. Preferred reporting items for systematic reviews and meta-analyses: the PRISMA statement. PLoS Med. 2009;6(7). doi:10.1371/journal. pmed.1000097
21. Guttormsen T, Høifødt TS, Silvola K, Burkeland O. The course first aid by suicidal danger (Kurset Førstehjelp ved selvmordsfare). Tidsskriftet Den Norske Legeforening. 2003;163:2281-2283. Available from: http://tidsskriftet.no/2003/08/tema-utdanning/kursetforstehjelp-ved-selvmordsfare. Accessed October 7, 2017.

22. King J, Hill K, Gleason A. All the world's stage: evaluating psychiatry roleplay based learning for medical students. Australas Psychiatry. 2015;23(1):76-79. doi:10.1177/1039856 214563846

23. Fossen P, Stoekel PR. Nursing students' perceptions of a hearing voices simulation and roleplay: preparation for mental health clinical practice. J Nurs Educ. 2016;55(4):203-208. doi:10.3928/0148483420160316-04

24. Wolff TK, Miller D. Using roleplaying to teach the psychiatric interview. J Group Psychother Psychodrama Sociom. 1993;46 (2):43-51.

25. Hill CE, Lent RW. A narrative and meta-analytic review of helping skills training: time to revive a dormant area of inquiry. Am Psychol Assoc. 2006;43(2):154-172.

26. Hill CE, Roffmann M, Stahl J, Friedmann S, Hummel A, Wallace C. Helping skills training for undergraduates: outcomes and prediction of outcomes. Am Psychol Assoc. 2008;55 (3):359-370.

27. Hill CE, Anderson T, Kline K, et al. Helping skills training for undergraduate students: who should we select and train? Couns Psychol. 2016;44(1):50-77. doi:10.1177/0011000015613142

28. Tavakol M, Dennick R. Making sense of Cronbach's alpha. Int J Med Educ. 2011;2:53-55. doi:10.5116/ijme.4dfb.8dfd
Advances in Medical Education and Practice

\section{Publish your work in this journal}

Advances in Medical Education and Practice is an international, peerreviewed, open access journal that aims to present and publish research on Medical Education covering medical, dental, nursing and allied health care professional education. The journal covers undergraduate education, postgraduate training and continuing medical education including emerging trends and innovative models linking education, research, and health care services. The manuscript management system is completely online and includes a very quick and fair peer-review system. Visit http://www.dovepress.com/testimonials.php to read real quotes from published authors. 